\title{
Estádio de abertura floral e qualidade pós-colheita em armazenamento de copo-de-leite ${ }^{(1)}$
}

\author{
MARIA LEANDRA RESENDE DE CASTRO (2), PATRÍCIA DUARTE DE OLIVEIRA PAIVA (2)* \\ PAULO ROBERTO CORREAA LANDGRAF ${ }^{(3)}$, MAYSA MATHIAS ALVES PEREIRA (3) \\ ROSEANE RODRIGUES SOUZA (2)
}

\begin{abstract}
RESUMO
A produção de flores de corte constitui uma atividade importante, cuja comercialização exige técnicas de conservação que contribuam para manter a qualidade floral após a colheita. Assim, objetivou-se avaliar diferentes pontos de abertura da espata, na colheita de hastes florais de copo-de-leite e seu efeito na conservação pós-colheita em duas formas de armazenamento, temperatura ambiente e em câmara fria. As hastes foram colhidas pela manhã, adotando 3 estádios diferentes de abertura da espata: espata fechada, $1 / 3$ aberta e aberta. As hastes florais foram padronizadas quanto ao tamanho da pseudo-haste em $40 \mathrm{~cm}$ e armazenadas em câmara fria a $4{ }^{\circ} \mathrm{C}$ e em temperatura ambiente a $20{ }^{\circ} \mathrm{C}$. As avaliações foram realizadas por 7 dias consecutivos, observando a qualidade visual das hastes florais, expansão da espata em comprimento e largura e a presença de pólen. Observou-se que não houve diferença qualitativa entre todos os estádios de colheita quando as hastes foram armazenadas em câmara fria, sendo que as hastes florais permaneceram na classe qualitativa A1, já em temperatura ambiente, as inflorescências colhidas fechadas e $1 / 3$ abertas apresentaram melhor qualidade, permanecendo na mesma classe qualitativa. As hastes colhidas fechadas e 1/3 abertas, armazenadas em câmara fria ou em temperatura ambiente, expandiram até o final da avaliação, sem apresentar necrose e murcha da espata, contudo, não completaram o processo de abertura. Conclui-se que as hastes florais colhidas com a espata fechada e espata 1/3 aberta continuam o processo de abertura da espata, mas não atingem a abertura completa, contudo apresentam maior durabilidade, independentemente da condição de armazenamento.
\end{abstract}

Palavras-chave: Zantedeschia aethiopica; ponto de colheita; floricultura; flores de corte; câmara fria.

\begin{abstract}
Stages of floral opening and post-harvest quality in storage of calla lily

The cut flowers production constitutes an important activity, which marketing requires conservation techniques that contribute to maintain post-harvest floral quality. The objective was to evaluate different points of the opening of the spathe, at the harvest of calla lily stems and its effect on post-harvest conservation of two forms of storage, room temperature and cold chamber. The stems were harvested in the morning, using three different stages of opening of the spathe: closed, semi-opened (1/3), and full opened. The floral stems were standardized by size of pseudo-stem $40 \mathrm{~cm}$ and storage in a cold chamber at $4{ }^{\circ} \mathrm{C}$ and room temperature to $20{ }^{\circ} \mathrm{C}$. The evaluations were conducted for 7 consecutive days, observing the visual quality of the floral stems, expansion of the spathe in length and width and the presence of pollen. It was observed that there was no qualitative difference between all stages of harvest when the stems were stored in a cold chamber, and the floral stems remained in the qualitative class A1, at room temperature the inflorescences harvested closed and semi-opened (1/3) showed better quality, remaining in the same quality class. Stems harvested closed and and semi-opened (1/3), stored in a cold chamber or at room temperature, expanded by the end of the assessment, without displaying necrosis and wilting of the spathe, however, did not complete the process of opening. We conclude that the floral stems harvested with a closed spathe and semi-opened (1/3) continue the process of opening of the spathe, but do not reach the completed opened, however have greater durability, regardless of the storage condition.
\end{abstract}

Keywords: Zantedeschia aethiopica; harvest stage; floriculture; cut flowers; cold chamber.

\section{INTRODUÇÃO}

As inflorescências de copo-de-leite estão entre as flores de corte mais produzidas em Minas Gerais, principalmente na região Sul do estado, onde predomina o clima ameno, indicado para o melhor desenvolvimento dessa espécie (LANDGRAF e PAIVA, 2009; ALMEIDA e PAIVA, 2012). No entanto, alguns aspectos relativos aos processos produtivos dessa espécie, principalmente os procedimentos de colheita e pós-colheita, ainda não estão elucidados.

A durabilidade pós-colheita é influenciada pelo estádio de desenvolvimento das flores na colheita. Geralmente, quando colhidas em um estádio de desenvolvimento mais aberto, essas flores possuem uma vida de vaso menor (NOWAK e RUDNICKI, 1990), uma vez que os processos catabólicos que levam à senescência se encontram em processo mais avançado. Outro aspecto a ser considerado na colheita de hastes florais completamente abertas é a presença de pólen, uma vez que a polinização acelera os sinais de senescência da espata, deixando a espata murcha (ALMEIDA e PAIVA, 2012).

Ao contrário, flores colhidas em um estádio precoce de desenvolvimento, dependendo da espécie, não atingem uma completa abertura, pois possuem menor reserva de carboidratos (GORSEL, 1994) ou ainda não atingiram o ponto de maturidade fisiológica. $\mathrm{O}$ estádio de abertura para colheita das flores varia de acordo com a espécie, sendo que rosa, lírio (BARBOSA, 2006),

\footnotetext{
(1) Trabalho recebido para publicação em 05/07/2012 e aprovado em 11/09/2014

(2) Universidade Federal de Lavras - UFLA, Departamento de Agricultura, Lavras-MG, 37200-000 *Autor correspondente: patriciapaiva@dag.ufla.br

(3) Universidade de Alfenas - UNIFENAS, Alfenas-MG, 37130-000.
} 
esporinha (FINGER et al, 2004) e gladíolo (SILVA et al, 2008) podem ser colhidas precocemente, antes da abertura total.

Para o copo-de-leite, recomenda-se que a colheita seja realizada com a espata aberta, mas com a ponta ainda virada para cima (TJIA, 1989; NOWAK e RUDNICKI, 1990; ALMEIDA et al. 2009). Quando colhidas nesse estágio e armazenadas em câmara fria, a durabilidade é de 7 dias, enquanto que, se mantidas em condição ambiente $\left(20^{\circ} \mathrm{C}\right) \mathrm{o}$ período de durabilidade é reduzido para 4 dias (ALMEIDA et al., 2009). No entanto, há poucos relatos de colheita em estádios de abertura mais precoce. Assim, objetivou-se avaliar diferentes estádios de abertura na conservação pós-colheita de hastes florais de copo-de-leite armazenadas em temperatura ambiente e em câmara fria.

\section{MATERIAL E MÉTODOS}

As hastes florais de copo-de-leite (Zantedeschia aethiopica) foram colhidas em produção comercial em Ilicínia, sul de Minas Gerais, no período da manhã e transportadas a seco e sem refrigeração por 60 minutos até o laboratório, onde foram colocadas em um recipiente com água potável. Utilizaram-se três pontos de colheita diferentes de abertura da espata: espata aberta (utilizado comercialmente), 1/3 aberta e espata fechada ou cartucho (Figura 1). As hastes florais foram acondicionadas em recipiente contendo $1000 \mathrm{~mL}$ de água potável e mantidas em dois ambientes diferentes, câmara fria a $4^{\circ} \mathrm{C}$ e em temperatura ambiente onde foram avaliadas até a perda da qualidade comercial.

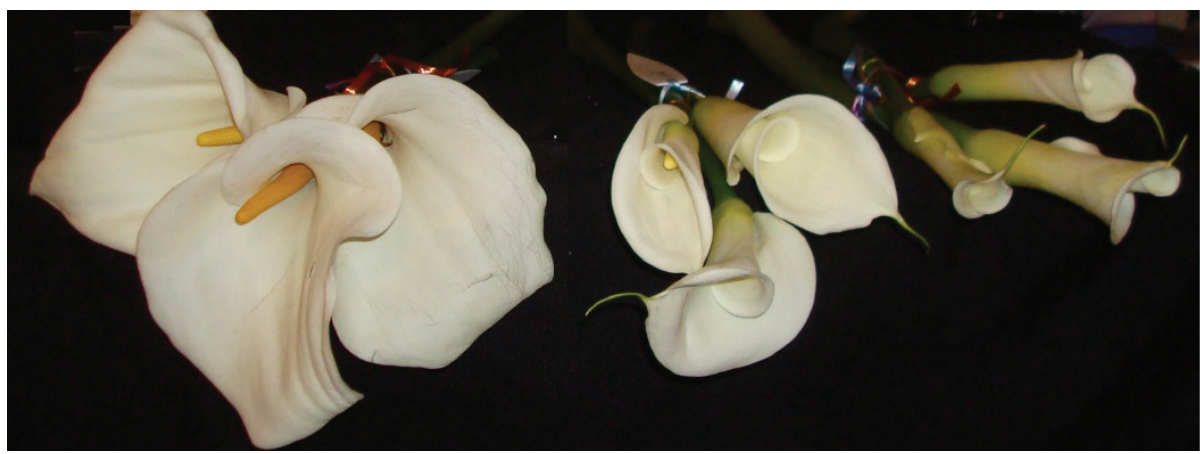

Figura 1. Diferentes estádios de colheita das hastes florais (da esquerda para direita): espata aberta, $1 / 3$ aberta e fechada (cartucho).

Figure 1. Different stages of harvest of floral stems (from left to right): closed, semi-opened (1/3), and full opened ("cartridge").

Durante o armazenamento, a temperatura média e a umidade relativa (UR) da câmara fria foram de $3,6^{\circ} \mathrm{C}$ e $93 \%$ e, em temperatura ambiente, $23^{\circ} \mathrm{C}$ e UR $42 \%$.

As hastes florais foram avaliadas diariamente por 7 dias, observando-se comprimento e largura da espata, presença de pólen e a análise visual da qualidade. Para analisar visualmente a qualidade das hastes florais adotou-se critério de classificação por notas, de acordo com Almeida et al., (2007). As inflorescências foram classificadas em A1: inflorescências túrgidas, ponta da espata inclinada, ausência de rugas ou necroses; A2: inflorescências túrgidas, base da espata levemente enrolada para baixo, ausência de rugas ou necroses; B: inflorescências túrgidas, ponta da espata levemente enrolada para baixo, presença de rugas, ausência de necroses; C: inflorescências murchas, ponta da espata enrolada para baixo, presença de necrose.

Foi utilizado o delineamento inteiramente casualizado, em esquema fatorial 3 (estádios de abertura) x 2 (tipos de armazenamento), totalizando 6 tratamentos com 4 repetições e 3 hastes florais por parcela. O modelo utilizado foi em parcela subdividida no tempo, sendo os estádios de abertura e o armazenamento na parcela, e os dias de avaliação na subparcela.
A análise de regressão das dimensões (comprimento e largura) das hastes florais foram realizadas com o auxílio do programa R (R DEVELOPMENT CORE TEAM, 2006). Para as análises qualitativas foi feito o teste Scott Knott a 5\% de probabilidade com auxílio do programa SISVAR (FERREIRA, 2011).

\section{RESULTADOS E DICUSSÃO}

De acordo com os resultados, verificou-se que não houve diferença qualitativa entre os estádios de colheita, espata aberta, 1/3 aberta e fechada, quando armazenadas em câmara fria, sendo que, durante os 7 dias de avaliação, as hastes florais permaneceram na classe qualitativa A1. No entanto, quando as hastes foram mantidas em temperatura ambiente (Tabela 1), os estádios de colheita, fechado e 1/3 aberto, mantiveram melhor qualidade, permanecendo na classe qualitativa A1 durante o mesmo período de avaliação. Estes estádios de colheita foram qualitativamente superiores em relação às hastes florais colhidas abertas, em todas as classes qualitativas estudadas. Desse modo, é possível colher as hastes florais em diferentes estádios de abertura, e não apenas com a espata completamente aberta. 
Tabela 1 Número de dias em que as hastes florais de copo-de-leite permaneceram nas classes qualitativas A1, A1+A2, A1+ $\mathrm{A} 2+\mathrm{B}$ em função dos estádios de colheita, em temperatura ambiente.

Table 1 Number of days that the floral stems of calla lily remained in qualitative classes $A 1, A 1+A 2, A 1+A 2+B$ as a function of stage of harvest, at room temperature

\begin{tabular}{|c|c|c|c|}
\hline \multicolumn{4}{|c|}{ Dias $^{*}$} \\
\hline Estádios de colheita & Classe A1 & Classe A1 + A2 & Classe $\mathrm{A} 1+\mathrm{A} 2+\mathrm{B}$ \\
\hline Fechada & $5,00 \mathrm{a}$ & $5,00 \mathrm{a}$ & $5,00 \mathrm{a}$ \\
\hline $1 / 3$ aberta & $4,53 \mathrm{a}$ & $4,85 \mathrm{a}$ & $4,93 \mathrm{a}$ \\
\hline Aberta & $3,00 \mathrm{~b}$ & $3,93 \mathrm{~b}$ & $3,93 \mathrm{~b}$ \\
\hline
\end{tabular}

*Médias seguidas pela mesma letra na coluna não diferem entre si pelo teste Scott-Knott, a 5\% de probabilidade.

Quanto à expansão da espata, as hastes florais armazenadas em câmara fria tiveram o processo de abertura mais lento, sendo observada pequena diferença entre a largura inicial e final, ao contrário das hastes que permaneceram em temperatura ambiente (Figura 2). As hastes florais colhidas fechadas e 1/3 abertas em temperatura ambiente atingiram a largura máxima de 5,0 cm aos 7 dias e 9,24 $\mathrm{cm}$ no $4^{\circ}$ dia de avaliação, mantendo ainda nível mais alto de qualidade. As hastes florais colhidas abertas apresentaram maior largura, $11,23 \mathrm{~cm}$, no $4^{\circ}$ dia de avaliação, reduzindo essa medida a partir desse ponto.
As hastes florais colhidas abertas e mantidas em temperatura ambiente tiveram redução na largura das espatas entre o primeiro e segundo dia de avaliação, provavelmente resultado do estresse da colheita, na qual as hastes perderam água tornando-se murchas, retomando a turgidez após o segundo dia de avaliação.

Quanto ao comprimento da espata, verificou-se influência do estádio de colheita, tipo de armazenamento e dias de avaliação (Figura 3).

\section{Câmara Fria}

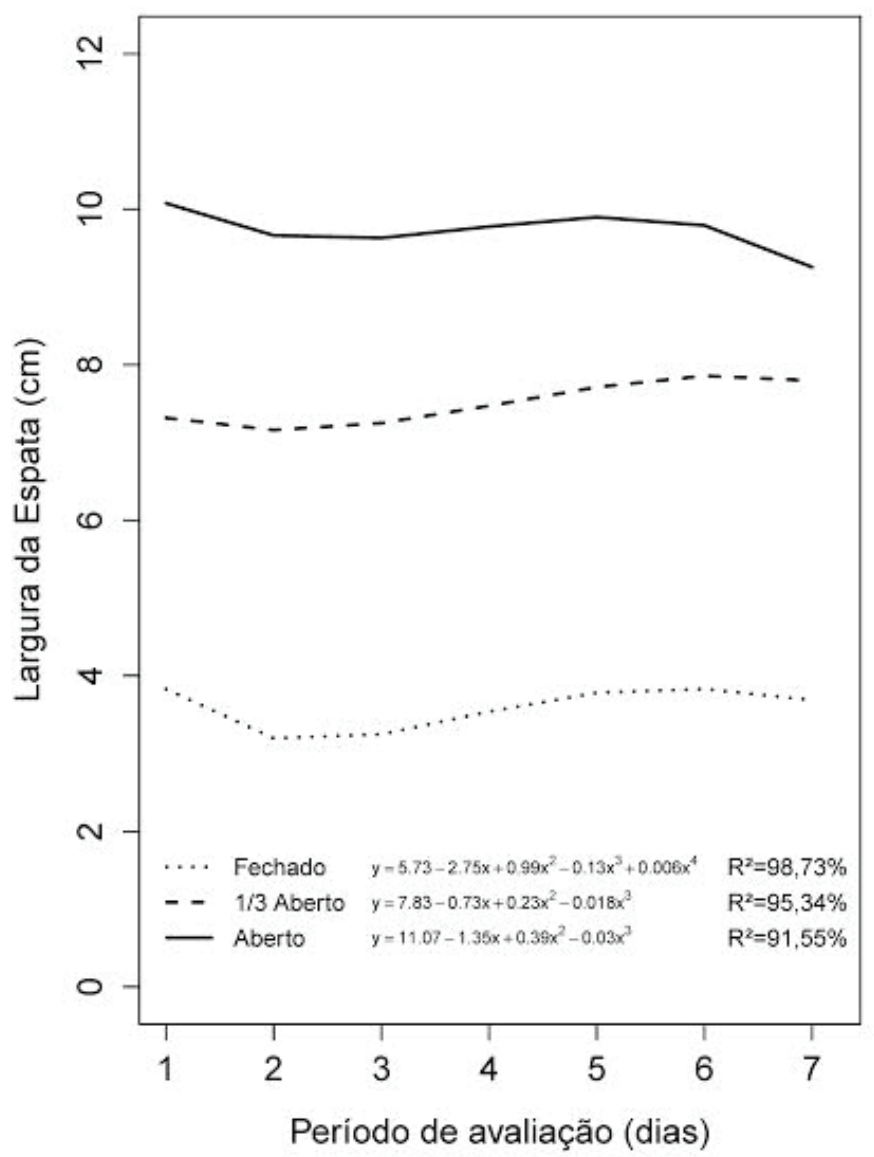

Temperatura Ambiente

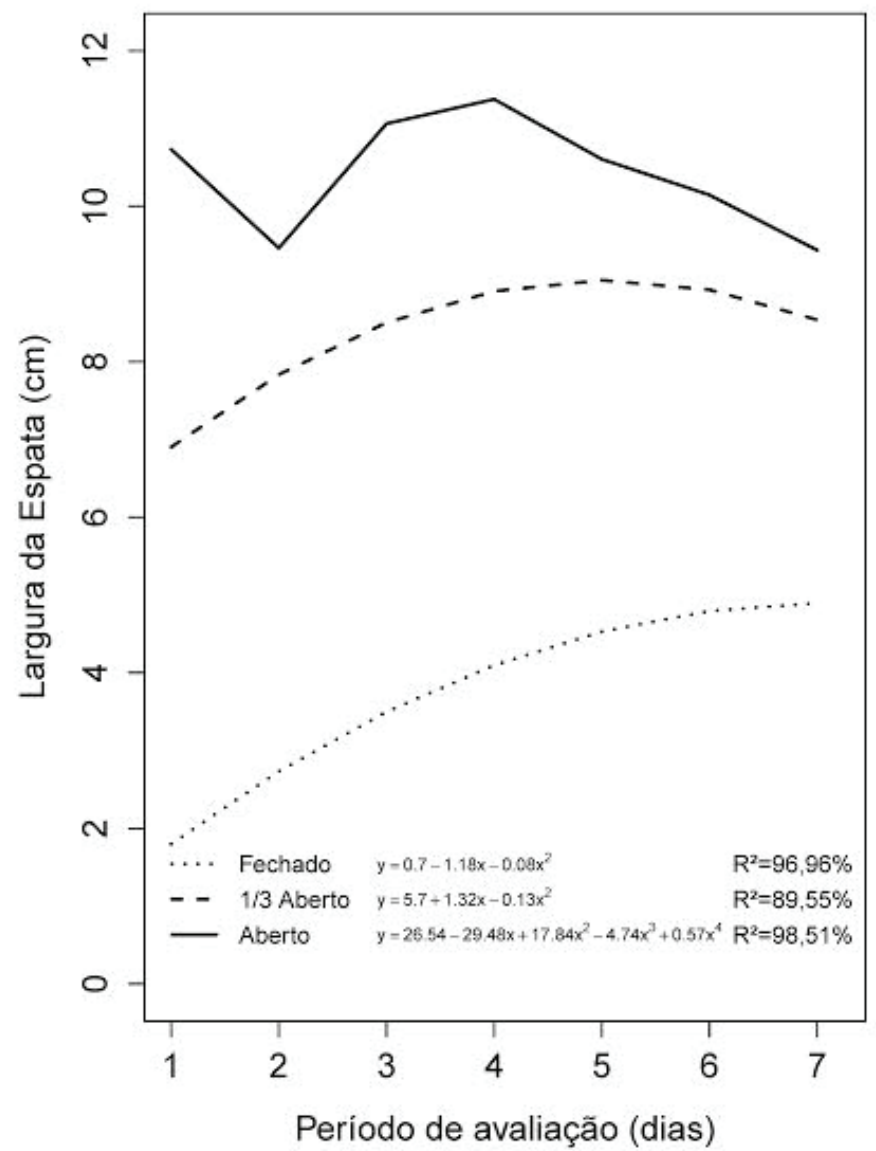

Figura 2. Largura média das espatas de copo-de-leite em função do estádio de colheita, tipo de armazenamento e período de avaliação.

Figure 2. Average width of the calla lily spathes according to the stage of harvesting, storage type and evaluation period. 
Câmara Fria

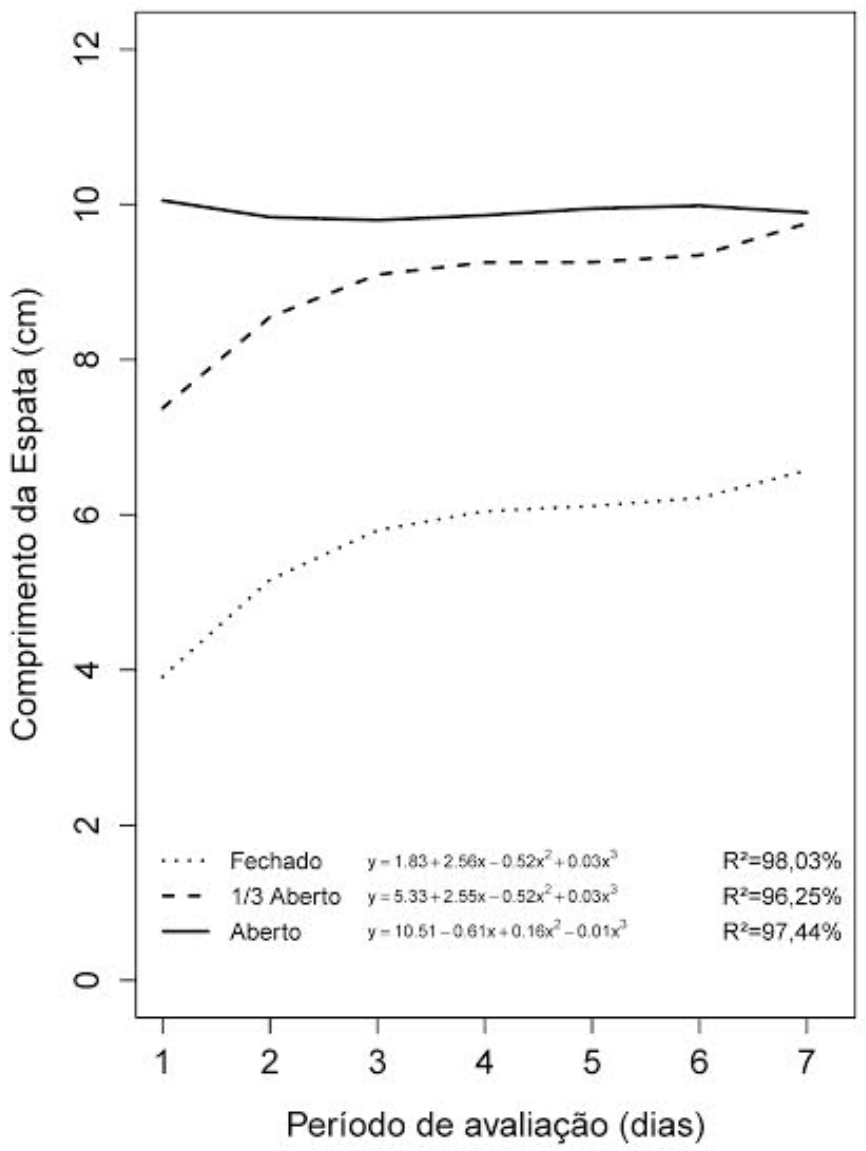

Temperatura Ambiente

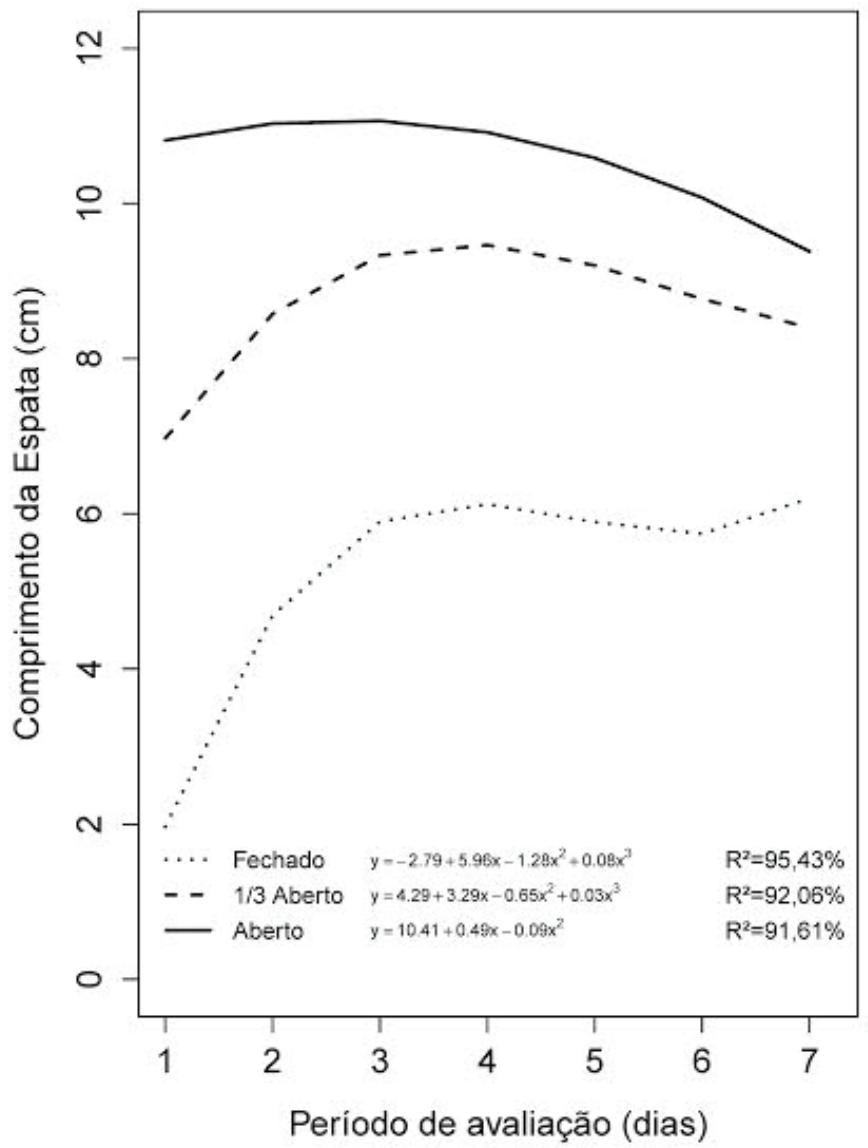

Figura 3. Comprimento médio das espatas de copo-de-leite em função do estádio de colheita, tipo de armazenamento e período de avaliação.

Figure 3. Average length of the calla lily spathes according to the stage of harvesting, storage type and evaluation period.

As hastes florais que foram armazenadas em câmara fria se expandiram lentamente em comparação com as dispostas em temperatura ambiente. Analisando o estádio de colheita $1 / 3$ aberta, com hastes mantidas em temperatura ambiente, observou-se comprimento máximo de $9,59 \mathrm{~cm}$ aos 5 dias.

As hastes colhidas fechadas e 1/3 abertas, armazenadas em câmara fria ou em temperatura ambiente, expandiram até o final da avaliação, sem apresentar necrose e murcha da espata, contudo, não completaram o processo de abertura.

Analisando a expansão das hastes florais, observou-se que aquelas mantidas em câmara fria tiveram dimensões máximas mais tardiamente quando comparadas com as dispostas em temperatura ambiente, indicando maior durabilidade, resultados observados também por Almeida et al. (2007).

Em temperatura ambiente, as hastes florais apresentaram aspecto amolecido e encharcado, o qual após corrida bacteriana e teste Gran, contatou-se tratar da bactéria Pectobacterium carotovorum (syn. Erwinia carotovora), o que não aconteceu para o armazenamento em câmara fria. Assim, o armazenado refrigerado é mais vantajoso, pois a baixa temperatura impede a proliferação de bactérias em hastes florais de copo-de-leite.
Não foi observada presença de pólen para todas as hastes florais, o que foi verificado também por Almeida et al. (2009), em hastes florais de copo-de-leite. Essa ausência é vantajosa para manutenção da qualidade das hastes florais, pois a polinização acelera os sinais de senescência, provocando murcha e abscisão da espata (ALMEIDA e PAIVA, 2012).

As hastes florais colhidas fechadas e $1 / 3$ abertas permaneceram mais tempo com qualidade superior, comprovando que a colheita precoce proporcionou maior vida de vaso, em comparação com as hastes colhidas com a espata completamente estendida, mesmo em temperatura ambiente, contrariando a indicação de Nowak e Rudnicki (1990), que indicam a colheita com a espata totalmente aberta. Inflorescências de lírio também mantiveram melhor qualidade quando colhidas antes da abertura total (BARBOSA et al., 2006).

A colheita precoce pode apresentar vantagens para mercados consumidores distantes, mantendo a qualidade por mais tempo e facilitando o transporte, uma vez que as hastes ocupam menor espaço, diminuindo também os danos nas espatas por essas estarem mais fechadas. 


\section{CONCLUSÕES}

As hastes florais de copo-de-leite colhidas com a espata fechada e espata $1 / 3$ aberta, mantidas tanto em câmara fria quanto em temperatura ambiente continuam o processo de abertura da espata, mas não atingem a abertura completa.

Maior vida de vaso foi observada para as hastes florais colhidas fechadas e 1/3 abertas tanto em câmara fria quanto em temperatura ambiente.

As hastes florais colhidas fechadas e $1 / 3$ abertas podem ser mantidas com qualidade em temperatura ambiente por 7 dias, ao contrário, quando colhidas abertas, permanecem por 3 dias.

As hastes florais armazenadas em câmara fria mantém boa qualidade por 7 dias, independente do estádio de abertura.

\section{AGRADECIMENTOS}

Os autores agradecem à FAPEMIG e ao $\mathrm{CNPq}$ pelo financiamento do projeto e bolsas.

\section{REFERÊNCIAS}

ALMEIDA, E.F.A.; PAIVA, P.D.O. Copo-de-leite, In: PAIVA, P.D.O.; ALMEIDA, E.F.A. Produção de flores de corte, v.1, Lavras: Editora UFLA, 2012. 678p.

ALMEIDA, E.F.A.; PAIVA, P.D.O.; LIMA, L.C.O.; RESENDE, M.L.; TAVARES, T.S.; CARNEIRO, D.N.M.; FONSECA, J.; PAIVA, R. Soluções de condicionamento para conservação pós-colheita de inflorescências de copo-de-leite armazenadas em câmara fria. Ciência Rural, Santa Maria, v.37, n.5, p.1442-1445, 2007.

ALMEIDA, E.F.A.; PAIVA, P.D.O.; LIMA, L.C.O.; RIBEIRO, M.N.O.; CARNEIRO, D.N.M.; RESENDE, M.L.; TAVARES, T.S.; PAIVA, R. Senescência de inflorescências de copo-de-leite: influência de diferentes armazenamentos e procedimentos póscolheita. Revista Brasileira de Horticultura Ornamental, Campinas, v.15, n.1, p. 71-76, 2009.
BARBOSA, J.G.;MEDEIROS, A.R.S.; FINGER, F.L.; REIS, F.P., ÁlVARES, V.S.; BARBOSA, M.S. Longevidade de inflorescências de lírio, de diferentes estádios de colheita, prétratadas com sacarose e tiossulfato de prata (STS). Ciência Rural, Santa Maria, v.36, n.1, p.99-104, 2006.

FERREIRA, D.F. Sisvar: a computer statistical analysis system. Ciência e Agrotecnologia, Lavras, v.35, n.6, p.10391042, 2011.

FINGER, F.L.; CARNEIRO, T. F.; BARBOSA, J.G. Senescência pós-colheita de inflorescências de esporinha (Consolida ajacis). Pesquisa Agropecuária Brasileira, Brasília, v.39, n.6, p.533-537, 2004.

GORSEL, R. Van. Postharvest technology of imported and trans-shipped tropical floricultural commodities. HortScience, Wallingford, v.29, n.9, p.979-981, 1994.

HE, S.; JOYCE, D.C.; IRVING, D.E.; FARAGHER, J.D. Stem end blockage in cut Grevillea "Crimson Yul-lo" inflorescences. Postharvest Biology and Technology, Washington, v.41, p.78-84, 2006.

LANDGRAF, P.R.C.; PAIVA, P.D.O. Produção de flores cortadas no estado de Minas Gerais. Ciência e Agrotecnologia, Lavras, v.33, n.1, p.120-126, 2009.

NOWAK, J.; RUDNICKI, R.M. Postharvest handling and storage of cut flowers, florist greens and potted plants. Portland: Timber Press, 1990. 210p.

R DEVELOPMENT CORE TEAM. R: A Language and Environment for Statistical Computing. R Foundation for Statistical Computing, Vienna, Austria, 2006.

SILVA, L.R.; OLIVEIRA, M.D.M.; SILVA, S.M. Manejo póscolheita de hastes florais de gladíolo (Gladiolos grandiflorus L.) ActaAgronómica, Palmira, v.57, n.2, p.129-135, 2008. TJIA, B.O. Zantedeschia. In: Handbook of flowering. Boca Ratan, v.6, p.753, 1989. 